\title{
Globe
}

Revue internationale d'études québécoises

\section{Réplique à propos de la recension de L'histoire sociale des idées au Québec (1760-1896)}

\section{Yvan Lamonde}

Volume 5, numéro 2, 2002

URI : https://id.erudit.org/iderudit/1000687ar

DOI : https://doi.org/10.7202/1000687ar

Aller au sommaire du numéro

Éditeur(s)

Globe, Revue internationale d'études québécoises

ISSN

1481-5869 (imprimé)

1923-8231 (numérique)

Découvrir la revue

Citer ce document

Lamonde, Y. (2002). Réplique à propos de la recension de L'histoire sociale des idées au Québec (1760-1896). Globe, 5(2), 184-186.

https://doi.org/10.7202/1000687ar d'utilisation que vous pouvez consulter en ligne.

https://apropos.erudit.org/fr/usagers/politique-dutilisation/ 


\section{REVUE INTERNATIONALE D'ÉTUDES QUÉBÉCOISES}

\section{Réplique}

\section{À propos de la recension de L'bistoire sociale des idées au Québec (1760-1896)}

La recension d'une synthèse semble tout autant un défi que sa rédaction. Dans sa recension de mon Histoire sociale des idées au Québec (1760-1896), parue dans un précédent numéro de la Revue internationale d'études québécoises, Globe, le recenseur évalue que j'ai " réécrit l'histoire du Québec ", que je propose "une nouvelle cohérence à des faits et à des trajectoires " et que dans l'ouvrage "la trame historique québécoise trouve un autre fil directeur ". De la même plume, il écrit "qu'on n'y propose aucun déplacement majeur de perspective ou de révision globale de l'historiographie ". Encore faudrait-il savoir ce qu'est un renversement copernicien de et dans l'historiographie et être capable de montrer qu'on est en position de voir les révisions globales. Pour ceux qui estiment qu'une synthèse ne peut être et n'est pas personnelle, j'aimerais indiquer quelques déplacements majeurs en sus de la "réécriture ", des "cohérences " nouvelles et du fil directeur "autre " de mon analyse.

Du strict point de vue des formes et des institutions culturelles, j'ai établi que le décollage culturel du Québec s'effectue au tournant de la décennie 1860. Pour ce faire, il ne s'agissait pas encore une fois de ressasser l'histoire de l'École patriotique et littéraire de Québec ; il fallait être capable, par des recherches personnelles tout autant que par la prise en compte des travaux existants, de montrer l'affaissement d'un premier décollage possible au moment des Rébellions, d'aligner les signes et les indicateurs quantitatifs sous l'Union et de faire voir la convergence des trajectoires de développement de l'instruction publique, de l'alphabétisation, de la presse, du mouvement associatif, de la librairie et des bibliothèques. J'ajouterai que pour identifier ce décollage culturel irréversible, j'ai conjugué l'analyse des formes culturelles à celle des grands courants d'idées. De même l'analyse qui met en place l'idée de la substitution d'une culture de masse à une culture associative, livresque et rhétoricienne vers 1880 ne se trouve pas étayée dans l'historiographie. Cette double périodisation du décollage et d'une substitution culturels ne renverse rien pour la simple et bonne raison qu'il n'y avait rien de sérieux à renverser. 
Du point de vue de l'histoire même des idées, l'ouvrage adopte une perspective civique, le point de vue de la société civile. D'où l'importance de la trame démocratique dans cette histoire, trame que j'ai par la suite dégagée dans une conférence au Musée de la Civilisation (Trajectoires de l'bistoire du Québec). C'est à la lumière de cette problématique qui fait " revoir * l'idée que les Canadiens français n'auraient pas voulu la démocratie pour eux-mêmes que je mets en place la trame du libéralisme et celle d'un Québec majoritairement et non consensuellement contre-révolutionnaire. Certes Claude Galarneau et Philippe Sylvain avaient fourni d'importants éléments; mais le suivi minutieux de cette trame permet dorénavant d'aller au-delà des impressions et des sentiments: la trame démocratique fut davantage présente sur toute la période qu'on ne l'avait établi sans qu'il faille pour autant gommer les moments forts ou dominants du conservatisme idéologique et politique.

Sur l'histoire du libéralisme, je prends certes appui sur Fernand Ouellet, sur Philippe Sylvain, sur Jean-Paul Bernard, mais outre le fait que j'enfile ces séquences dans une logique, je marque les points tournants, je donne toute sa profondeur historique au discours de Laurier de 1877 , je distingue le libéralisme radical du radicalisme modéré et en appelle à une histoire un peu plus définitive du dernier, qui finit par être dominant. Et pour donner toute sa perspective au discours de Laurier à propos de la dimension anglaise plus que française du libéralisme canadien-français, il fallait avoir fait place non seulement à l'admiration canadienne-française pour la Constitution anglaise ou à la reproduction, dans la colonie, de l'Entente cordiale de la nouvelle et de l'ancienne mère-patrie mais tout autant au mimétisme des formes culturelles anglophones par les francophones qu'aux accrocs à la démocratie de ces anglophones colonisateurs.

Suivant la logique du signataire du compte rendu, il faudrait se demander ce que serait un " déplacement majeur " des interprétations des Rébellions de 1837 et de 1838 . Je lui laisse le plaisir d'imaginer des scénarios. Pour ma part, j'apporte trois éléments nouveaux à la compréhension de ces événements marquants. D'abord, une analyse de l'importance des "libertés anglaises. de 1791 à 1830 qui font l'admiration du Parti Canadien/Patriote, de Papineau et du Canadien. Cette analyse doit faire comprendre que le revirement de Papineau et des Patriotes pour les libertés américaines est non seulement progressif mais surtout tardif et que la conviction républicaine dispose ainsi de peu de temps pour 
générer dans la population en 1837 une conscience efficace. Ensuite, j'ai tenté de montrer qu'à cet état d'avancement relatif d'une conscience coloniale de dépendance se greffait un état d'avancement culturel tout aussi relatif où la conscience émancipatoire ne s'est guère exprimée dans une littérature, dans un mouvement savant de retour sur les traditions populaires ou dans des symboles nationaux. Enfin, en étudiant la connaissance que les Bas-Canadiens avaient des mouvements d'émancipation nationalitaire en Europe et dans les Amériques et en scrutant l'usage fait de cette information, j'ai fait voir le partage de la presse sinon de la population sur la similitude ou non des événements internationaux et locaux, les attentes espérées ou déçues à l'égard de la France et des États-Unis et la conscience claire ou masquée de faire face à un Empire naissant qui avait réduit Napoléon à Trafalgar et à Waterloo. Cette analyse, qui documente l'ancienneté des revendications " constitutionnelles ", qui scande l'indignation, l'impatience et l'exaspération des Patriotes, entend faire voir l'état des, choses au moment où, les Résolutions Russell tombant comme une chape de plomb, une exaspération volatile amène moins à finir une révolution qu'à sauver ses chefs, ses biens, sa dignité.

La prise en compte du contexte international pour comprendre les Rébellions valait tout autant pour saisir les héritages politico-culturels des différentes "métropoles : : que doit cette culture québécoise à son histoire et à sa composante françaises, britanniques, américaines et vaticanes ? La repondération de l'importance de ces marqueurs à partir d'une conscience historique d'appartenance à l'Amérique a suscité suffisamment de débats pour qu'on puisse y voir un déplacement de vision.

Ce sont là quelques exemples d'interprétations nouvelles et globales que je crois avoir documentées et articulées. Je reste ouvert à des façons différentes de faire l'histoire des idées au Québec (voir mon article dans le dernier Cabier des Dix, année 2001) et je suis on ne peut plus curieux de me faire expliquer les forces, méthodes et apports inédits d'une "sociologie historique des idées". Qu'y trouverait-on d'inédit et de spécifique?

Yvan Lamonde Université McGill 